\title{
STRUKTUR DAN KOMPOSISI JENIS VEGETASI DI HUTAN SEKUNDER: STUDI KASUS KHDTK LABANAN PROVINSI KALIMANTAN TIMUR (Structure And Species Composition Of Tree In Secondary Forest: A case study at KHDTK Labanan, East Borneo Province)
}

\author{
"Karmilasanti, dan/and M. Fajri \\ Balai Besar Penelitian dan Pengembangan Ekosistem Hutan Dipterokarpa \\ Jl. A.W. Syahranie No.68 Sempaja, Samarinda \\ Telp. (0541) 206364; Fax. (0541) 742298 \\ E-mail: "karmilasanti.ahmad@gmail.com; fajririmbawan@gmail.com
}

Tanggal diterima: 27 Februari 2020; Tanggal disetujui: 25 Juni 2020; Tanggal direvisi: 12 Agustus 2020

\begin{abstract}
Unproductive forests in the form of secondary forest tend to be converted into forest plantation, agriculture and other land uses. Even though the secondary forest can still be restored using native commercial species. This study aimed to determine the structure and composition of stands, the potential of residual stands, and natural regeneration of the secondary forest in KHDTK Labanan. The research was carried out through vegetation inventory and vegetation analysis to calculate stand potential, natural regeneration, Importance Value Index (IVI), and species diversity. The results showed the structure of commercial species stands in secondary forests in the Labanan KHDTK followed an inverted "J" shaped exponential curve as well as stand structure of natural forest. The potential of commercial species stands with diameter of $20 \mathrm{~cm}$ and above was $22.30 \mathrm{~m}^{3} / \mathrm{ha}$ with a number of trees more than 25 trees/ha. Natural regeneration of commercial species for pole were 121 stems $/$ ha, sapling were 47 stems/ha, and seedling were 50 stems/ha. The dominant

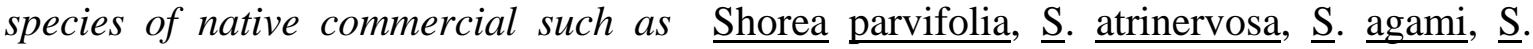
hopeifolia, Madhuca malaccensis, and Koilodepas sp needs to be maintained and nurtured in order to ensure the continuity the natural succession and diversity, thus become a source of seed trees. The species diversity index in the sekunder forest was high to moderate.
\end{abstract}

Keywords : Secondary forest, diversity, composition, potency

\begin{abstract}
ABSTRAK
Hutan tidak produktif berupa hutan sekunder cenderung dikonversi menjadi hutan tanaman, perkebunan, dan peruntukkan lainnya, meskipun hutan sekunder masih bisa dipulihkan dengan menggunakan jenis-jenis komersial setempat. Penelitian ini bertujuan untuk mengetahui struktur dan komposisi tegakan, potensi tegakan tinggal, dan permudaan alami pada hutan sekunder di KHDTK Labanan. Penelitian dilakukan melalui inventarisasi vegetasi dan analisis vegetasi guna menentukan potensi tegakan, kondisi permudaan alami, Indeks Nilai Penting (INP), dan keragaman jenis. Hasil penelitian menunjukkan struktur tegakan jenis komersial pada hutan sekunder di KHDTK Labanan mengikuti kurva eksponensial berbentuk "J" terbalik seperti struktur tegakan pada berbagai kondisi hutan alam. Potensi tegakan jenis komersial diameter $20 \mathrm{~cm}$ ke atas sebesar 22,30 $\mathrm{m}^{3} / \mathrm{ha}$ dengan jumlah pohon lebih dari 25 pohon/ha. Permudaan alami jenis komersial untuk tingkat tiang 121 pohon/ha, pancang 47 batang/ha, dan semai 50 batang/ha. Dengan demikian, pada hutan sekunder KHDTK Labanan tidak diperlukan pengayaan. Jenis unggulan setempat yang dominan antara lain jenis Shorea parvifolia, S. atrinervosa, S. agami, S. hopeifolia,
\end{abstract}


Madhuca malaccensis, dan Koilodepas sp. perlu dijaga dan dipelihara agar suksesi alami dan keanekaragaman terus berlanjut, serta menjadi sumber benih. Indeks keanekaragaman jenis di hutan sekunder KHDTK Labanan termasuk tinggi sampai sedang.

Kata kunci : Hutan sekunder, keanekaragaman, komposisi, potensi

\section{PENDAHULUAN}

Menurut Kementerian Lingkungan Hidup dan Kehutanan (2018) hutan sekunder di Indonesia mencakup luasan sekitar $22,5 \%$ atau 42,25 juta ha dari luas tutupan lahan di Indonesia. Hutan sekunder ini terbentuk karena adanya aktivitas penebangan oleh pengusahaan hutan (Margono, Potapov, Turubanova, Stolle, \& Hansen, 2014). Terjadinya hutan sekunder menimbulkan resiko terjadinya penurunan keanekaragaman hayati (Pryde, Holland, Watson, Turton, \& Nimmo, 2015). Hal ini didukung oleh Arbainsyah, Longh, Kustiawan, \& Snoo (2014), bahwa kelimpahan dan komposisi jenis pohon di hutan sekunder bekas tebangan lebih rendah dibandingkan dengan hutan primer.

Menurut Peraturan Direktur Jenderal Planologi Kehutanan Nomor P.1/VIIIPSDH/2015, hutan sekunder adalah seluruh kenampakan hutan dataran rendah, perbukitan, dan pegunungan yang telah menampakkan bekas penebangan, termasuk daerah perkebunan, semak belukar, atau lahan terbuka. Menurut Soerianegara \& Indrawan (2014) hutan sekunder ada dua yaitu sekunder muda yang didominasi oleh jenis pionir dan hutan sekunder tua yang sudah ditumbuhi oleh jenis-jenis dipterokarpa terutama jenis Shorea sp. Pada Kawasan Hutan Dengan Tujuan Khusus (KHDTK) Labanan terdapat hutan bekas tebangan, dimana kondisi hutannya telah mengalami penurunan potensi akibat dari kegiatan penebangan liar yang dilakukan oleh masyarakat sekitar kawasan. Karmilasanti \& Abdurachman (2017) menyatakan bahwa hutan sekunder bekas tebangan di KHDTK Labanan memiliki kerapatan tegakan berkisar antara 10,88 $15,29 \mathrm{~m}^{2} /$ ha termasuk kategori lahan tidak produktif.
Struktur vegetasi pada hutan sekunder memiliki komponen yang saling terkait dan berhubungan erat. Hubungan tersebut digambarkan pada struktur vegetasi sebagai salah satu komponen penyusun ekosistem dalam hutan. Struktur vegetasi atau struktur tegakan selain dipengaruhi oleh kerapatan tegakan, ternyata dipengaruhi juga oleh penyebaran individu tingkat pohon dan permudaan yang ada dalam kawasan hutan tersebut (Saridan \& Soegiharto, 2012).

Menurut Susanty (2015) berdasarkan peta Penunjukan Kawasan Hutan dan Perairan Provinsi Kalimantan Timur bahwa kawasan Hutan Labanan awalnya berfungsi sebagai Hutan Produksi Tetap (HP) dan telah dibebani Ijin Usaha Pemungutan Hasil Hutan Kayu Hutan Alam (IUPHHK-HA) PT Inhutani I Unit Labanan yang bermitra kerja dengan Perusahaan Umum Daerah PT Hutan Sanggam Labanan Lestari. Berdasarkan Surat Keputusan Menteri Kehutanan Nomor 64/Menhut-II/2012 tersebut, maka KHDTK Labanan merupakan kawasan hutan alam tropis yang ditunjukkan khusus untuk penelitian dan pengembangan dengan total luas 7.959,10 ha dan berada di Kabupaten Berau, Kalimantan Timur. Kondisi tutupan lahannya terdiri atas areal berhutan 7.742 ha dan tidak berhutan 215,9 ha (Susanty, 2015). Saat ini kondisi KHDTK Labanan telah mengalami degradasi akibat penebangan liar, perambahan lahan, dan kebakaran. Di KHDTK Labanan terdapat 67 marga dan 26-29 jenis dari famili dipterokarpa (Saridan, 2012; Saridan \& Fajri, 2014). Pada areal tersebut terdapat hutan sekunder bekas tebangan kategori tidak produktif dan potensi rendah yang perlu diketahui kondisi tegakan dan permudaannya sebagai dasar untuk merehabilitasinya. 
Berdasarkan permasalahan di atas, maka penelitian ini bertujuan untuk mengetahui struktur dan dinamika struktur tegakan pada hutan sekunder. Informasi tesebut berguna untuk bahan rekomendasi jenis-jenis komersial yang diperlukan dalam kegiatan pengayaan/rehabilitasi hutan sekunder bekas tebangan tidak produktif atau hutan sekunder tua potensi rendah khusus yang ada di sekitarnya dan tempat lain dengan tipe agroklimat yang sama.

\section{METODOLOGI}

\section{A. Lokasi dan Waktu Penelitian}

Penelitian dilakukan pada tahun 2017 di areal hutan sekunder area KHDTK Labanan, Desa Labanan Makmur, Kecamatan Teluk Bayur, Kabupaten Berau, Provinsi Kalimantan Timur. Hutan sekunder yang menjadi lokasi penelitian berada di areal bekas tebangan (Logged Over Area - LOA). Lokasi penelitian berada di areal bekas perambahan. Titik koordinat lokasi penelitian berada pada $01^{\circ} 56^{\prime} 36,60^{\prime \prime}$ $01^{\circ} 56^{\prime} 45,07^{\prime \prime}$ Lintang Utara dan $117^{\circ} 12^{\prime} 40,74^{\prime \prime}-117^{\circ} 13 ’ 30,32$ Bujur Timur dengan ketinggian lokasi antara 108-120 m dpl (Gambar 1).

\section{B. Metode}

\section{Pembuatan plot}

Metode penelitian menggunakan teknik purposive sampling. Plot penelitian berbentuk bujur sangkar berukuran $100 \mathrm{~m} \mathrm{x}$ $100 \mathrm{~m}$ (1 ha). Di dalam plot tersebut dilakukan pengambilan data vegetasi untuk tingkat pohon (diameter setinggi dada/dbh $\geq 20,0 \mathrm{~cm}$ ). Setiap plot dibagi dalam $25 \mathrm{sub}$ plot $(20 \mathrm{~m} \times 20 \mathrm{~m}$ ) untuk mengidentifikasi tingkat pohon (struktur, sebaran jenis, dan mengukur diameter dan tinggi pohon sampai tinggi bebas cabang guna menentukan potensi tegakan). Di dalam plot pengamatan tingkat pohon, dibuat sub plot pengamatan permudaan tingkat tiang $(10 \mathrm{~m} \times 10 \mathrm{~m})$, sub plot pengamatan tingkat pancang $(5 \mathrm{~m} \quad \mathrm{x} 5 \mathrm{~m})$, dan sub plot pengamatan tingkat semai $(2 \mathrm{~m} \times 2 \mathrm{~m})$. Pengamatan dilakukan pada 25 sub plot yang tersedia. Plot pengamatan tersebut dapat dilihat pada Gambar 2 dan 3.

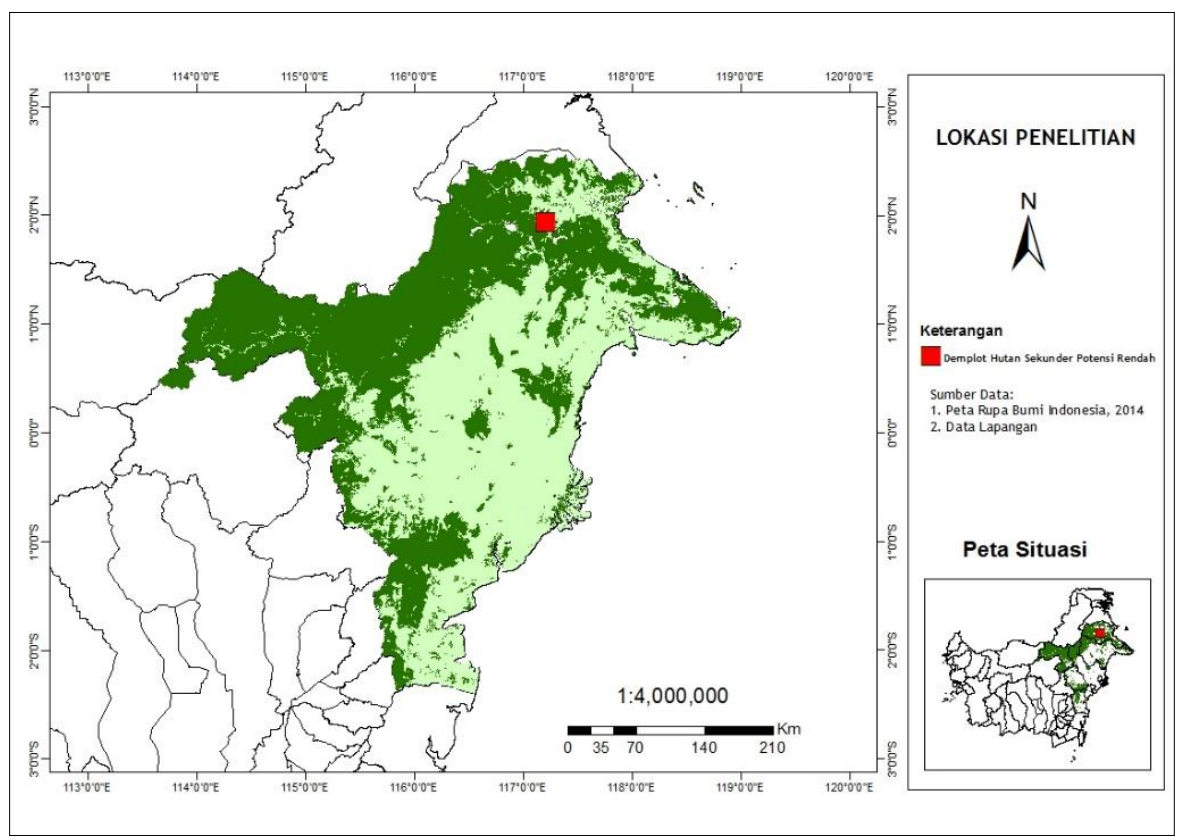

Gambar (Figure) 1. Lokasi penelitian di KHDTK Labanan, Kabupaten Berau, Propinsi Kalimantan Timur (The study site at KHDTK Labanan, Berau District of East Kalimantan Province) 


\begin{tabular}{|c|c|c|c|c|c|}
\hline \multirow{2}{*}{$\Phi$} & \multicolumn{5}{|c|}{$100 \mathrm{~m}$} \\
\hline & $\mathrm{J} 1$ & $\mathrm{~J} 2$ & $\mathrm{~J} 3$ & $\mathrm{~J} 4$ & J5 \\
\hline & PU5 & PU6 & PU15 & PU16 & PU25 \\
\hline & PU4 & PU7 & PU14 & PU17 & PU24 \\
\hline \multirow[t]{3}{*}{$100 \mathrm{~m}$} & PU3 & PU8 & PU13 & PU18 & PU23 \\
\hline & PU2 & PU9 & PU12 & PU19 & PU22 \\
\hline & PU1 & PU10 & PU11 & PU20 & PU21 \\
\hline & $20 \mathrm{~m}$ & $20 \mathrm{~m}$ & $20 \mathrm{~m}$ & $20 \mathrm{~m}$ & $20 \mathrm{~m}$ \\
\hline & rangan & arks): $\mathbf{J}$ & $\begin{array}{l}\text { lur (line) } \\
20 \mathrm{~m} \\
\text { ince betu } \\
\text { jang plo }\end{array}$ & $\begin{array}{l}\mathrm{J}=\text { petak } \\
=\text { jarak } \\
\text { sub plo } \\
\text { lot lengt }\end{array}$ & $\begin{array}{l}\text { tar (sub } \\
\operatorname{tar} P \\
100 \mathrm{~m}\end{array}$ \\
\hline
\end{tabular}

Gambar (Figure) 2. Desain analisis vegetasi (The design of vegetation analysis)

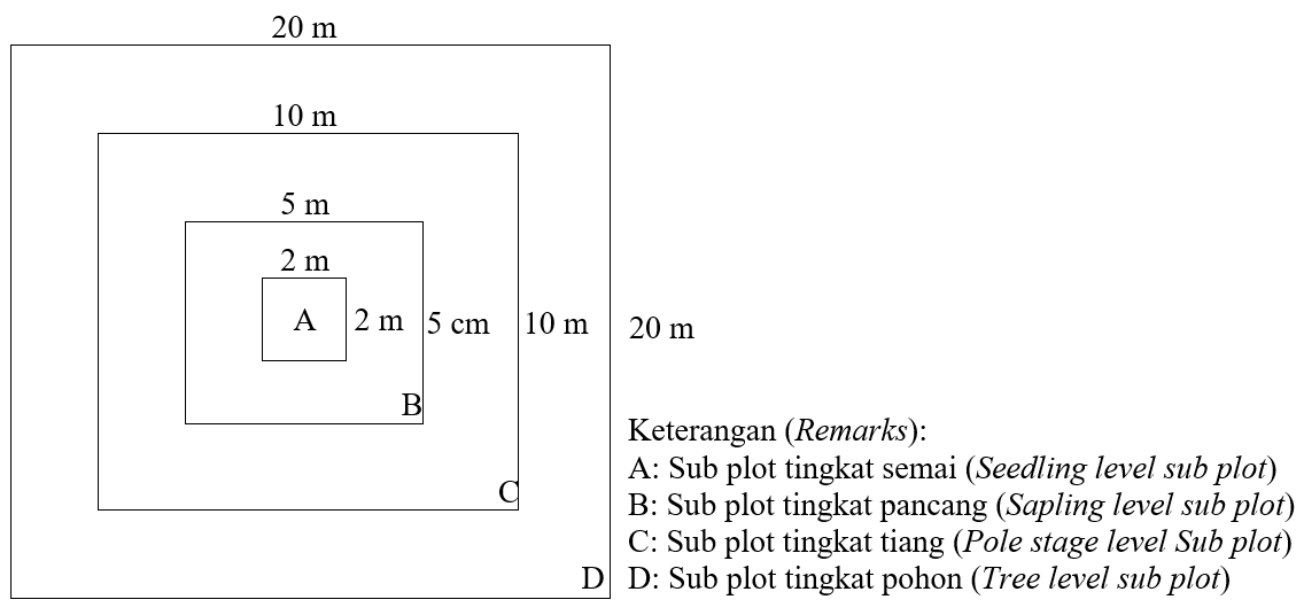

Gambar (Figure) 3. Desain inventarisasi vegetasi (The design of vegetation inventory)

\section{Pengambilan data}

Data yang dikumpulkan berupa nama jenis untuk tingkat pohon dan permudaan (tingkat tiang, pancang, dan semai). Tingkat pohon adalah semua jenis pohon yang berdiameter setinggi dada (dbh) $20 \mathrm{~cm}$ ke atas. Tingkat tiang adalah jenis-jenis pohon dengan dbh $10 \mathrm{~cm}$ sampai kurang dari $20 \mathrm{~cm}$, Tingkat pancang adalah jenisjenis pohon dengan tinggi lebih dari $1,5 \mathrm{~m}$ dan dbh kurang dari $10 \mathrm{~cm}$. Tingkat semai jenis-jenis pohon dengan tinggi kurang dari 1,5 m (Widiyatno et al., 2017). Pengukuran diameter menggunakan pita meter dan tinggi pohon diukur menggunakan clinometer. 


\section{Analisis Data}

Untuk mengetahui komposisi jenis dan struktur tegakan dilakukan analisis vegetasi (Fajri \& Saridan, 2012; Ismaini, Lailati, Rustandi, \& Sunandar, 2015). Variabel yang diamati pada masing-masing tingkat pertumbuhan vegetasi sebagai berikut:

1. Vegetasi tingkat permudaan (semai, pancang, dan tiang) meliputi: jenis vegetasi dan jumlah individu tiap jenis.

2. Vegetasi tingkat pohon meliputi: jenis vegetasi, jumlah individu tiap jenis, diameter setinggi dada (dbh), dan tinggi pohon sampai tinggi bebas cabang.

Berdasarkan data hasil analisis vegetasi, maka diketahui kekayaan jenis yang ada di areal tersebut. Kemudian setiap jenis vegetasi dihitung Kerapatan (K), Kerapatan Relatif (KR), Frekuensi (F), Frekuensi Relatif (FR), Dominansi (D), dan Dominansi Relatif (DR) dengan rumus sebagai berikut (Mukrimin, 2011):

1. Potensi tegakan merupakan volume tegakan berdiameter $20 \mathrm{~cm}$ ke atas $\left(\mathrm{m}^{3} / \mathrm{ha}\right)$ :

$\Sigma$ Volume tingkat pohon sampai $\mathrm{V}=\frac{\text { tinggi bebas cabang dari suatu plot }}{\text { Luas plot }}$

2. Kerapatan (K) adalah jumlah individu suatu jenis tumbuhan dalam suatu luasan tertentu, nilai kerapatan dihitung dengan rumus:

Kerapatan $(\mathrm{K})=\frac{\Sigma \text { Individu suatu jenis }}{\text { Luas plot }}($ batang $/$ ha $)$

3. Kerapatan relatif (KR) merupakan persentase kerapatan suatu jenis terhadap total kerapatan seluruh jenis $(\%)$ :

$\mathrm{KR}=\frac{\text { Kerapatan suatu jenis }}{\text { Kerapatan seluruh jenis }} \mathrm{X} 100 \%$

4. Frekuensi suatu jenis tumbuhan (F) adalah jumlah plot ditemukannya jenis tersebut dari sejumlah plot yang dibuat, rumusnya sebagai berikut:
$\mathrm{F}=\frac{\Sigma \text { Plot ditemukan suatu jenis }}{\text { Seluruh plot }}$

5. Frekuensi relatif (FR) adalah persentase frekuensi spesies tumbuhan tertentu dibagi total frekuensi seluruh jenis tumbuhan $(\%)$ :

$\mathrm{FR}=\frac{\text { Frekuensi suatu jenis }}{\text { Frekuensi seluruh jenis }} \mathrm{X}$ 100\%

6. Dominansi (D) merupakan proporsi permukaan tanah yang ditutupi oleh proyeksi luas bidang dasar suatu jenis tertentu, rumusnya sebagai berikut:

$\mathrm{D}=\frac{\Sigma \text { Luas bidang dasar suatu jenis }}{\text { Luas plot }}$

7. Dominan relatif (DR) merupakan persentase dominansi suatu jenis terhadap dominansi seluruh jenis (\%):

$\mathrm{DR}=\frac{\text { Dominansi suatu jenis }}{\text { Dominansi seluruh jenis }} \times 100 \%$

8. Indeks Nilai Penting (INP) merupakan parameter kuantitatif yang bisa dipakai dalam menyatakan tingkat dominansi suatu spesies dalam suatu komunitas tumbuhan (Mukrimin, 2011). Rumus umum yang digunakan untuk menentukan nilai INP tingkat pohon adalah Kerapatan Relatif + Frekuensi Relatif + Dominansi Relatif, sedangkan INP tingkat tiang/pancang/semai adalah Kerapatan Relatif + Frekuensi Relatif.

9. Indeks keanekaragaman jenis merupakan derajat keanekaragaman jenis vegetasi di suatu kawasan menggunakan rumus Indeks ShannonWiener:

$$
H^{\prime}=-\sum_{i=1}^{n} p i(\ln p i)
$$


Dimana :

$$
\begin{aligned}
\mathrm{H}= & \begin{array}{l}
\text { Indeks keanekaragaman jenis } \\
\text { (indeks Shannon-Wiener), }
\end{array} \\
\mathrm{P} i & =\text { Kelimpahan relatif dari jenis ke-i, } \\
\mathrm{Ni} & =\text { Jumlah individu jenis ke- } \mathrm{i}, \\
\mathrm{N} & =\text { Jumlah total individu jenis, } \\
\mathrm{ln} & =\text { Logaritma natural. }
\end{aligned}
$$

Tingkat keanekaragaman jenis Shannon didefinisikan sebagai berikut:

1) $\mathrm{H}^{\prime}>3=$ keanekaragaman jenis tinggi pada suatu kawasan;

2) $1 \leq \mathrm{H}^{\prime} \leq 3=$ keanekaragaman jenis sedang;

3) $\mathrm{H}^{\prime}<1=$ keanekaragaman jenis rendah.

\section{HASIL DAN PEMBAHASAN}

\section{A. Hasil}

\section{Struktur tegakan dan potensi tegakan}

Jumlah jenis komersial per ha pada tingkat pohon didominasi oleh kelas diameter 20-29,9 cm, yaitu 35 pohon/ha. Jenis komersial kelas diameter $30 \mathrm{~cm}$ ke atas terdapat 18 pohon/ha. Total jenis komersial yang potensial dijadikan pohon inti di areal penelitian sebesar 53 pohon/ha yang terdiri dari 26 pohon/ha jenis komersial dipterokarpa dan 27 pohon/ha jenis komersial non dipterokarpa. Struktur tegakan horizontal di hutan sekunder menunjukkan bahwa semakin besar kelas diameter, maka semakin berkurang jumlah pohonnya. Jumlah kelompok jenis non komersial (72 pohon/ha) cenderung lebih tinggi daripada jenis komersial dipterokarpa dan komersial non dipterokarpa (53 pohon/ha). Hasil analisis vegetasi ditemukan empat marga, yaitu Dipterocarpus, Hopea, Shorea, dan Vatica. Grafik struktur tegakan dapat dilihat pada Gambar 4. dan nama-nama jenis vegetasi disajikan pada Lampiran 1.

Potensi tegakan diameter $20 \mathrm{~cm}$ ke atas paling banyak dari kelompok jenis nonkomersial yaitu $48,66 \mathrm{~m}^{3} / \mathrm{ha}$. Untuk kelompok jenis komersial sebesar 22,30 $\mathrm{m}^{3} / \mathrm{ha}$ yang terdiri atas kelompok jenis dipterokarpa $15,65 \mathrm{~m}^{3} /$ ha dan komersial non dipterokarpa sebesar $6,65 \mathrm{~m}^{3} / \mathrm{ha}$. Di lokasi penelitian potensi pohon jenis komersial diameter $30 \mathrm{~cm}$ ke atas kurang dari $20 \mathrm{~m}^{3} /$ ha, sehingga masuk dalam kategori hutan sekunder potensi rendah. Volume tegakan hutan sekunder di areal penelitian memiliki potensi tegakan 15,18 $\mathrm{m}^{3} /$ ha dengan jumlah pohon 18 pohon/ha. Potensi tegakan di areal penelitian disajikan pada Tabel 1 dan 2 .

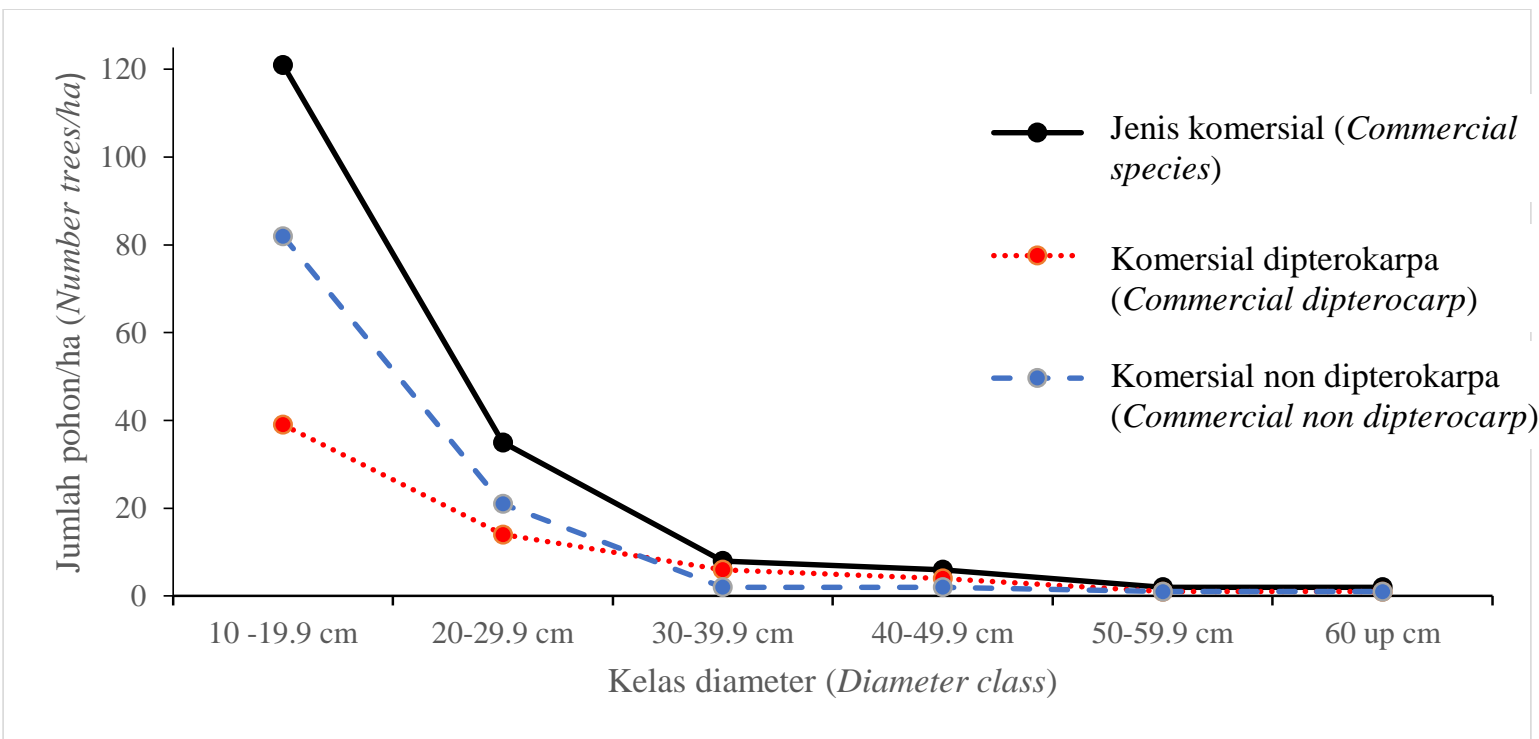

Gambar (Figure) 4. Grafik jumlah pohon per ha untuk kelompok jenis komersial (The graphic of trees number per hectare for commercial species group) 
Tabel (Table) 1. Potensi tegakan pada plot penelitian (The potential stands in the research plot)

Volume tegakan untuk kelas diameter (Stand volume for diameter classes) $\left(\mathrm{m}^{3} / \mathrm{ha}\right)$

Diameter 20-29,9 cm Diameter $30 \mathrm{~cm}$ ke atas

\begin{tabular}{|c|c|c|c|c|c|c|}
\hline \multirow[b]{2}{*}{$\begin{array}{c}\text { Kelompok } \\
\text { jenis (Species } \\
\text { groups) }\end{array}$} & \multicolumn{2}{|c|}{ (Diameter 20-29,9 cm) } & \multicolumn{2}{|c|}{ (Diameter $30 \mathrm{~cm} \mathrm{up)}$} & \multirow[b]{2}{*}{$\begin{array}{c}\text { Jumlah } \\
\text { pohon } \\
\text { (Tree } \\
\text { number) } \\
\text { (Pohon/ha) } \\
\text { (Trees/ha) }\end{array}$} & \multirow[b]{2}{*}{$\begin{array}{c}\text { Volume } \\
\text { tegakan } \\
\text { (Stand } \\
\text { volume }) \\
\left(\mathrm{m}^{3} / \mathrm{ha}\right)\end{array}$} \\
\hline & $\begin{array}{c}\text { Jumlah } \\
\text { pohon } \\
\text { (Tree } \\
\text { number } \\
\text { (Pohon/ha) } \\
\text { (Trees/ha) }\end{array}$ & $\begin{array}{c}\text { Volume } \\
\text { tegakan } \\
\text { (Stand } \\
\text { volume }) \\
\left(\mathrm{m}^{3} / \mathrm{ha}\right)\end{array}$ & $\begin{array}{c}\text { Jumlah } \\
\text { pohon } \\
\text { (Tree } \\
\text { number) } \\
\text { (Pohon/ha) } \\
\text { (Trees/ha) }\end{array}$ & $\begin{array}{c}\text { Volume } \\
\text { tegakan } \\
\text { (Stand } \\
\text { volume }) \\
\left(\mathrm{m}^{3} / \mathrm{ha}\right)\end{array}$ & & \\
\hline
\end{tabular}

\begin{tabular}{lllllll}
\hline 1. Komersial & 14 & 3,54 & 12 & 12,11 & 26 & 15,65
\end{tabular}

dipterokarpa

(Commercial dipterocarp)

2. Komersial non dipterokarpa (Commercial non dipterocarp)

3. Non

(Non commercial)

4. Komersial

Commercial $(1+2)$

5. Semua jenis (All species) $(3+4)$

\begin{tabular}{rrrrrr}
35 & 7,12 & 18 & 15,18 & 53 & 22,30 \\
79 & 17,21 & 46 & 53,75 & 125 & 70,96 \\
\hline
\end{tabular}

Tabel (Table) 2. Permudaan alam di plot penelitian (The natural regeneration in the research plot)

\begin{tabular}{lccc}
\hline Kelompok jenis (Species groups) & $\begin{array}{c}\text { Tingkat tiang } \\
\text { (Pole level) } \\
(\text { Batang/ha) } \\
(\text { Stem/ha })\end{array}$ & $\begin{array}{c}\text { Tingkat pancang } \\
\text { (Sapling level) } \\
(\text { Batang/ha) } \\
(\text { Stem/ha })\end{array}$ & $\begin{array}{c}\text { Tingkat semai } \\
\text { (Seedling level }) \\
(\text { Batang/ha }) \\
(\text { Stem/ha })\end{array}$ \\
\hline $\begin{array}{c}\text { 1. Komersial dipterokarpa } \\
(\text { Commercial dipterocarp })\end{array}$ & 39 & 13 & 14 \\
$\begin{array}{c}\text { 2. Komersial non dipterokarpa } \\
(\text { Commercial non dipterocarp })\end{array}$ & 82 & 34 & 36 \\
3. Komersial (Commercial) $(1+2)$ & 121 & 47 & 50 \\
\hline
\end{tabular}


Tabel (Table) 3. Komposisi jenis dipterocarpa pada plot penelitian (The composition of dipterocarp species in the research plot)

\begin{tabular}{|c|c|c|c|c|c|c|c|}
\hline $\begin{array}{c}\text { Tingkat } \\
\text { vegetasi } \\
\text { (Vegetation } \\
\text { level) }\end{array}$ & $\begin{array}{l}\text { Nama lokal } \\
\quad \text { (Local } \\
\text { name })\end{array}$ & $\begin{array}{c}\text { Jenis } \\
\text { (Spesies) }\end{array}$ & $\begin{array}{r}\text { Keluarga } \\
(\text { Famili })\end{array}$ & $\mathrm{KR}(\%)$ & $\mathrm{FR}(\%)$ & $\mathrm{DR}(\%)$ & $\operatorname{INP}(\%)$ \\
\hline \multirow{3}{*}{$\begin{array}{l}\text { 1. Semai } \\
\text { (Seedling) }\end{array}$} & Selagan batu & S. atrinervosa & Dipterocarpaceae & 3,85 & 2,44 & - & 6,29 \\
\hline & Keruing & D. stellatus & Dipterocarpaceae & 2,31 & 2,44 & - & 4,75 \\
\hline & Meranti putih & S. agami & Dipterocarpaceae & 2,31 & 2,44 & - & 4,75 \\
\hline \multirow{3}{*}{$\begin{array}{l}\text { 2. Pancang } \\
\text { (Sapling) }\end{array}$} & Meranti putih & S. agami & Dipterocarpaceae & 3,64 & 3,19 & - & 6,83 \\
\hline & Tengkawang & S. beccariana & Dipterocarpaceae & 3,64 & 2,13 & - & 5,76 \\
\hline & Keruing & D. stellatus & Dipterocarpaceae & 0,91 & 1,06 & - & 1,97 \\
\hline \multirow{3}{*}{$\begin{array}{l}\text { 3. Tiang } \\
\text { (Pole) }\end{array}$} & Damar asam & S. hopeifolia & Dipterocarpaceae & 2,89 & 2,88 & 2,40 & 8,17 \\
\hline & $\begin{array}{l}\text { Meranti sarang } \\
\text { punai }\end{array}$ & S. parvifolia & Dipterocarpaceae & 2,48 & 2,40 & 2,82 & 7,71 \\
\hline & Tengkawang & S. beccariana & Dipterocarpaceae & 2,48 & 2,88 & 2,02 & 7,38 \\
\hline \multirow[t]{3}{*}{$\begin{array}{l}\text { 4. Pohon } \\
\text { (Tree) }\end{array}$} & $\begin{array}{l}\text { Meranti sarang } \\
\text { punai }\end{array}$ & S. parvifolia & Dipterocarpaceae & 2,97 & 5,37 & 2,64 & 10,98 \\
\hline & Tengkawang & S. beccariana & Dipterocarpaceae & 2,43 & 2,68 & 2,64 & 7,75 \\
\hline & Damar asam & S. hopeifolia & Dipterocarpaceae & 2,43 & 1,56 & 2,64 & 6,63 \\
\hline
\end{tabular}

Keterangan (Remarks): KR =Keragaman Relatif (Relative Density), FR = Frekuensi Relatif (Relative Frequency $), \mathrm{DR}=$ Dominansi Relatif $($ Relative Dominance $), \mathrm{INP}=$ Indeks Nilai Penting (Important Value Index)

Tabel (Table) 4. Komposisi jenis non dipterokarpa pada plot penelitian (The composition of non-dipterocarp species in the research plot)

\begin{tabular}{|c|c|c|c|c|c|c|c|}
\hline $\begin{array}{c}\text { Tingkat vegetasi } \\
\text { (Vegetation } \\
\text { level) }\end{array}$ & $\begin{array}{c}\text { Nama lokal } \\
\text { (Local name) }\end{array}$ & Jenis (Species) & $\begin{array}{l}\text { Keluarga } \\
\text { (Family) }\end{array}$ & $\begin{array}{l}\mathrm{KR} \\
(\%)\end{array}$ & $\begin{array}{l}\text { FR } \\
(\%)\end{array}$ & $\begin{array}{l}\text { DR } \\
(\%)\end{array}$ & $\begin{array}{l}\text { INP } \\
(\%)\end{array}$ \\
\hline \multirow{3}{*}{$\begin{array}{l}\text { 1. Semai } \\
\text { (Seedling) }\end{array}$} & Bantun & Koilodepas sp. & Euphorbiaceae & 17,69 & 9,76 & - & 27,45 \\
\hline & Parang-parang & $\begin{array}{l}\text { Fordia } \\
\text { splendidissima }\end{array}$ & Leguminosae & 6,15 & 7,32 & - & 13,47 \\
\hline & Katiau & $\begin{array}{l}\text { Madhuca } \\
\text { malaccensis }\end{array}$ & Sapotaceae & 6,92 & 6,10 & - & 13,02 \\
\hline \multirow{3}{*}{$\begin{array}{l}\text { 2. Pancang } \\
\text { (Sapling) }\end{array}$} & Bantun & Koilodepas sp. & Euphorbiaceae & 9,09 & 8,51 & - & 17,60 \\
\hline & Katiau & M. malaccensis & Sapotaceae & 8,18 & 8,51 & - & 16,69 \\
\hline & Asam gunung & Cleistanthus sp. & Euphorbiaceae & 9,09 & 7,45 & - & 16,54 \\
\hline \multirow[t]{3}{*}{ 3. Tiang (Pole) } & Katiau & M. malaccensis & Sapotaceae & 8,68 & 5,29 & 30,47 & 44,44 \\
\hline & Mahang & $\begin{array}{l}\text { Macaranga } \\
\text { hypoleuca }\end{array}$ & Euphorbiaceae & 4,96 & 4,33 & 10,17 & 19,46 \\
\hline & Asam gunung & Cleistanthus sp. & Phyllanthaceae & 4,55 & 4,33 & 6,60 & 15,47 \\
\hline \multirow{3}{*}{$\begin{array}{l}\text { 4. Pohon } \\
\text { (Tree) }\end{array}$} & Katiau & M. malaccensis & Sapotaceae & 7,03 & 16,36 & 3,96 & 27,35 \\
\hline & Mahang & $\begin{array}{l}\text { Macaranga } \\
\text { hypoleuca }\end{array}$ & Euphorbiaceae & 5,14 & 10,26 & 3,63 & 19,02 \\
\hline & Jambu-jambu & Syzigium sp. & Myrtaceae & 4,05 & 8,11 & 3,63 & 15,80 \\
\hline
\end{tabular}

Keterangan (Remarks): KR = Keragaman Relatif (Relative Density), FR = Frekuensi Relatif (Relative Frequency), DR $=$ Dominansi Relatif $($ Relative Dominance $), \mathrm{INP}=$ Indeks Nilai Penting (Important Value Index) 
Tabel (Table) 5. Indeks keanekaragaman jenis di hutan sekunder KHDTK Labanan, Kalimantan Timur (The diversity index of spesies at research site)

\begin{tabular}{lcl}
\hline $\begin{array}{c}\text { Kelas vegetasi } \\
\text { (Level of vegetation) }\end{array}$ & $\begin{array}{c}\text { Indeks keanekaragaman jenis } \\
\text { (Species diversity index) }\end{array}$ & Kategori (Categori) \\
\hline 1. Pohon (Tree) & 4,27 & Tinggi (High) \\
2. Tiang (Pole) & 2,99 & Sedang (Medium) \\
3. Pancang (Sapling) & 3,60 & Tinggi (High) \\
4. Semai (Seedling) & 3,20 & Tinggi (High) \\
\hline
\end{tabular}

Tabel 3 menunjukkan bahwa jenis dipterokarpa mendominasi di semua tingkat vegetasi. Untuk tingkat semai didominasi oleh jenis S. atrinervosa, D. stellatus, dan S. agami. Tingkat pancang didominasi oleh jenis S. agami, S. beccariana, dan D. stellatus. Tingkat tiang didominasi oleh jenis S. hopeifolia, S. parvifolia, dan S. beccariana. Tingkat pohon didominasi oleh jenis S. parvifolia, S. beccariana, dan S. hopeifolia. Nilai Indeks Nilai Penting (INP) untuk tingkat semai yang tertinggi adalah jenis S. atrinervosa (6,29\%), tingkat pancang S. agami $(6,83 \%)$, tingkat tiang S. hopeifolia $(8,17 \%)$ dan tingkat pohon S. parvifolia $(10,98 \%)$.

Kelompok komersial jenis non dipterokarpa di semua tingkat vegetasi ada dua famili yaitu suku Euphorbiaceae dan Sapotaceae. Pada tingkat semai jenis yang paling dominan adalah Koilodepas sp. $(27,45 \%)$, tingkat pancang yaitu Koilodepas sp. $(17,60 \%)$, tingkat tiang ialah Madhuca malaccensis $(44,44 \%)$, dan tingkat pohon adalah M. malaccensis (27,35\%). Hasil analisis vegetasi untuk kelompok jenis non dipterokarpa disajikan pada Tabel 4.

\section{Indeks keanekaragaman jenis}

Tabel 5 menunjukkan bahwa indeks keanekaragaman jenis pada hutan sekunder pada tingkat pohon, pancang, dan semai antara 3,3-4,27, kecuali untuk tingkat tiang hampir mendekati tiga. Hal ini menunjukkan nilai indeks keanekaragaman jenis pada studi area pada umumnya termasuk dalam kategori tinggi sampai sedang. Nilai indeks keanekaragaman jenis pada studi area bisa dilihat pada Tabel 5 .

\section{B. Pembahasan}

\section{Struktur tegakan horizontal}

Struktur tegakan menggambarkan hubungan antara kelas diameter dan jumlah pohon (Herianto, 2017). Struktur tegakan di hutan sekunder di KHDTK Labanan dikelompokkan menjadi dua kelompok, yaitu struktur tegakan kelompok jenis komersial dipterokarpa dan komersial non dipterokarpa. Hasilnya menunjukkan bahwa kerapatan kelas diameter pada tingkat pohon (diameter $\geq 20 \mathrm{~cm}$ ) di hutan sekunder relatif sama dengan kerapatan kelas diameter di berbagai formasi hutan. Kerapatan tertinggi di hutan sekunder KHDTK Labanan terdapat pada kelas diameter $20 \mathrm{~cm}$ sampai dengan $29,9 \mathrm{~cm}$. Semakin besar ukuran diameter pohon, semakin menurun kerapatannya (Istomo \& Hartarto, 2019). Bertambahnya ukuran diameter pohon, maka semakin sedikit ditemukan jumlah pohon yang tersebar pada kelas diameter tersebut. Bentuk yang umum dari distribusi kelas diameter mengikuti bentuk kurva eksponensial "J" terbalik, artinya semakin besar kelas diameternya, maka semakin kecil kerapatannya (Istomo \& Dwisutono, 2016). Rendahnya jumlah kelompok diameter besar disebabkan karena dampak pemanenan seperti penebangan dan penyaradan serta karena adanya kegiatan persiapan lahan sebelum dilakukan penanaman jenis-jenis meranti atau jenis komersil lainnya (Widiyatno, Soekotjo, Naiem, Hardiwinoto, \& Purnomo, 2011). 


\section{Komposisi jenis dipterokarpa dan non dipterokarpa}

Komposisi jenis menunjukkan jumlah jenis dan keberadaan jenis-jenis dalam suatu kawasan hutan, termasuk tingkat penguasaan jenis di dalam komunitasnya. Jenis yang dominan menunjukkan INP yang tinggi. INP adalah angka yang menggambarkan tingkat penguasaan suatu jenis dalam vegetasi, dan menunjukkan keberadaan suatu jenis tersebut dalam komunitasnya (Asmayannur \& Syam, 2012). Makin besar INP, maka makin besar pula peranan jenis tersebut dalam komunitasnya.

Di hutan sekunder KHDTK Labanan, kelompok jenis dipterokarpa yang mendominasi di setiap tingkat vegetasi ditemukan berbeda-beda. Pada tingkat semai didominasi oleh jenis S. atrinervosa, tingkat pancang oleh S. agami, tingkat tiang oleh S. hopeifolia, dan tingkat pohon oleh S. parvifolia. Keempat tingkat pertumbuhan tegakan tersebut, kelompok jenis dipterokarpa yang paling mendominasi adalah S. parvifolia. INP tingkat pohon jenis S. parvifolia di hutan sekunder sebesar $10,98 \%$. Nilainya jauh lebih kecil dibandingkan dengan INP S. parvifolia di areal plasma nutfah PT ITCI Hutani Manunggal yang mencapai $19,13 \%$ dan 31,92\% (Sari \& Karmilasanti, 2015). Jenis S. parvifolia merupakan spesies pohon hutan hujan tropis dataran rendah paling umum di Asia Tenggara dan bisa dijadikan indikator perubahan dalam distribusi dan luasnya hutan hujan tropis (Iwanaga et al., 2012). Jenis tersebut mendominasi hutan hujan tropis dataran rendah setidaknya di Sumatera dan Kalimantan Bagian Timur (Iwanaga et al., 2012). Jenis S. parvifolia merupakan jenis Shorea yang memiliki sebaran cukup luas (Saridan \& Wahyudi, 2017). Jenis ini dikenal sebagai meranti sarang punai, merupakan jenis kayu komersil dan tumbuh cepat baik di dataran rendah dan dataran tinggi (Seng, Ling, Lau, \& Jusoh, 2011).

Kelompok jenis non dipterokarpa di beberapa tingkat pertumbuhan tegakan juga berbeda-beda. Untuk tingkat vegetasi pohon kelompok jenis non dipterokarpa terdapat tiga suku yang mendominasi yaitu Sapotaceae, Euphorbiaceae, dan Myrtaceae dengan tiga jenis pohon yang berbeda yaitu Madhuca malaccensis, Macaranga hypoleuca dan Syzigium sp. Untuk tingkat pohon, hasil penelitian ini sama dengan hasil penelitian Fajri \& Saridan, (2012) yang juga dilakukan pada hutan sekunder di kawasan KHDTK Labanan, dimana jenis pohon yang dominan adalah jenis pohon dari non dipterokarpa dengan jenis yang berbeda yaitu jenis Anthocephalus chinensis, M. hypoleuca, dan Macaranga sp. Sama juga dengan hasil penelitian Fajri \& Garsetiasih (2019) pada lahan bekas tambang galian $\mathrm{C}$ di KHDTK Labanan, dimana jenis pohon yang dominan adalah jenis non dipterokarpa dengan jenis yang berbeda, yaitu jenis kayu ara (Ficus sp.), laban telor (Callicarpa pentandra), dan petai cina (Leucaena leucocephala).

Jenis pohon M. malaccensis merupakan jenis pohon yang bisa dimanfaatkan sebagai tumbuhan obat tradisional dari hutan rawa gambut dan bagian yang digunakan sebagai obat adalah bagian dari biji (Denny \& Kalima, 2016). Jenis dominan berikutnya adalah $\mathrm{M}$. hypoleuca. Menurut Utama, Syamsuardi, \& Arbain (2012) bahwa genus Macaranga dikenal sebagai tumbuhan pionir yang mudah tumbuh pada hutan sekunder dan lahan terbuka yang memiliki potensi untuk dikembangkan dalam program rehabilitasi hutan dan lahan. M. hypoleuca merupakan jenis pohon yang bisa tumbuh sampai $30 \mathrm{~m}$, hidup di hutan bekas kebakaran, kadang ditemukan juga di jalan sepanjang jalan hutan campuran dipterokarpa bekas tebangan serta pada areal sekunder di hutan primer (Amirta, Angi, Ramadhan, Kusuma, Wiati, \& Haqiqi, 2017). Jenis berikutnya yang dominan adalah Syzigium sp; menurut Kuswandi, Sadono, Supriyatno, \& Marsono (2015) bahwa jenis ini bisa tumbuh mendominasi pada tingkatan pohon di hutan alam bekas tebangan. 
Untuk tingkat tiang, jenis yang mendominasi hampir sama dengan tingkat pohon, yaitu M. malaccensis, M. hypoleuca dan Cleistanthus sp. Jenis Cleistanthus sp. merupakan jenis pohon yang tumbuh pada tipe hutan sekunder bekas tebangan di hutan hujan tropika dataran rendah. Kondisi topografinya bergelombang dengan lereng antara 8-35\% dan jenis tanah termasuk tipe tropodult (USDA) atau sama dengan Podsolik Merah Kuning (Hadiah, Yuzammi. \& Purnomo, 2019; Samsoedin \& Heriyanto, 2010).

Untuk tingkat pancang, jenis yang mendominasi adalah Koilodepas sp., M. malaccensis dan Cleistanthus sp. Koilodepas adalah genus asal Asia kecil yang terdiri dari sembilan spesies yang tersebar mulai dari India hingga Cina Selatan, lalu ke selatan hingga bagian barat Kepulauan Melayu dan Papua (Welzen, 2010). Jenis K. brevipes, K. laevigatum, dan $\mathrm{K}$. pectinatum merupakan jenis endemik di Kalimantan.

Untuk tingkat semai, yang dominan adalah jenis Koilodepas sp., F. splendidissima, M. malaccensis. Jenis F. splendidissima sangat berperan pada pemulihan ekosistem hutan karena mampu tumbuh pada areal bekas terbakar, dan bisa dijadikan pohon untuk kegiatan reklamasi pasca tambang batubara (Adman, 2012). Kemampuan simbiosis jenis ini juga berperan menyuburkan tanah karena bisa memfiksasi nitrogen dari udara akan meningkatkan kandungan nitrogen dalam tanah.

\section{Indeks keanekaragaman jenis}

Hasil penelitian menunjukkan bahwa indeks keanekaragaman jenis di areal hutan sekunder KHDTK Labanan lebih rendah daripada di hutan primer, hutan bekas tebangan (LOA) umur 1 tahun, dan LOA umur 23 tahun. Menurut Susanty (2015) bahwa indeks keanekaragaman jenis pada areal hutan primer, LOA umur 1 tahun, dan LOA umur 23 tahun berturut-turut 4,73; 4,42; dan 4,54. Namun hasil penelitian ini memiliki indeks keanekaragaman jenis yang lebih tinggi jika dibandingkan dengan hasil penelitian Fajri \& Garsetiasih (2019) yang dilakukan di lahan pasca tambang galian $\mathrm{C}$ umur 7-8 tahun pasca tambang.

$$
\text { Adanya perbedaan indeks }
$$

keanekaragaman jenis di berbagai kondisi hutan alam diakibatkan proses ekofisiologis yang dinamis dan berkorelasi dengan kondisi iklim, kondisi hara, rentang toleransi jenis, faktor biogeografi (Kenfack, Chuyong, Condit, Russo, \& Thomas, 2014), serta dipengaruhi oleh kondisi habitat hutan (Narahari, Ostertag, Asner, Cordell, Hubbell, \& Sack, 2014). Tingkat keanekaragaman jenis bisa menjadi indikator untuk melihat kemampuan suatu komunitas menyeimbangkan komponennya dari berbagai gangguan yang timbul (Kuswanda \& Barus, 2017). Tingkat keanekaragaman jenis dapat mempengaruhi gangguan lingkungan dan kestabilan dari komunitas tumbuhan pada suatu lokasi (Hilwan, 2012).

\section{Implikasi analisis vegetasi terhadap struktur, komposisi jenis dan potensi tegakan di hutan sekunder}

Hasil analisis vegetasi menunjukkan bahwa lokasi penelitian masuk dalam kriteria dan ciri hutan sekunder tua potensi rendah mengacu pada Peraturan Direktur Jenderal Konservasi Sumberdaya Alam dan Ekosistem Nomor P.12/KSDAE-Set/2015 bahwa vegetasi didominasi oleh jenis-jenis klimaks yang memiliki tutupan tajuk yang dominan. Jenis-jenis tersebut bisa dijadikan pohon induk karena telah memenuhi kriteria, yaitu jenis komersial unggulan setempat. Jika jumlah pohon per ha untuk diameter $10 \mathrm{~cm}$ ke atas kurang dari 200 pohon, dan permudaan di bawah 1.000 anakan alam per ha, maka kawasan tersebut termasuk LOA rusak (Peraturan Direktur Jenderal Konservasi Sumberdaya Alam dan Ekosistem Nomor P.12/KSDAE-Set/2015; Peraturan Menteri Kehutanan Nomor. P.64/Menhut-II/2014).

Potensi tegakan pohon komersial pada vegetasi hutan sekunder di KHDTK Labanan diameter $20 \mathrm{~cm}$ ke atas sebesar 
22,30 $\mathrm{m}^{3} / \mathrm{ha}$ dengan jumlah pohon komersial 53 pohon/ha. Tingkat permudaan alam tiang terdapat 121 pohon/ha, pancang 47 batang/ha, dan semai 50 batang/ha. Hal ini menunjukkan areal tersebut diketegorikan sebagai hutan sekunder bekas tebangan potensi rendah.

Dengan demikian, hutan sekunder KHDTK Labanan tidak perlu dilakukan pengayaan/rehabilitasi. Hal ini karena pohon inti (jenis komersial berdiameter 20 $\mathrm{cm}$ ke atas) lebih dari 25 pohon/ha, tingkat tiang lebih dari 75 batang/ha, namun tingkat pancang kurang dari 150 batang/ha dan semai kurang dari 400 batang/ha. Pengayaan diperlukan apabila semua tingkat vegetasi (pohon, tiang, pancang, dan semai) tidak terpenuhi dari angka kecukupan yang dipersyaratkan, sedangkan jika keberadaan jumlah vegetasi per ha ada salah satu terpenuhi, maka tidak perlu pengayaan.

\section{KESIMPULAN DAN SARAN}

\section{A. Kesimpulan}

Hutan sekunder di KHDTK Labanan memiliki struktur tegakan secara eksponensial berbentuk huruf "J" terbalik, yaitu semakin kecil pohonnya, maka jumlah jenis per ha semakin tinggi. Struktur tegakan di hutan sekunder bekas tebangan potensi rendah tersebut mirip dengan beberapa kondisi hutan alam. Pada kelompok jenis diperokarpa untuk diameter $20 \mathrm{~cm} \mathrm{ke}$ atas didominasi oleh genus Shorea dan jenis yang paling dominan adalah S. parvifolia. Untuk kelompok jenis non dipterokarpa didominasi dua famili yaitu Euphorbiaceae dan Sapotaceae. Permudaan alam kelompok jenis dipterokarpa yang dominan untuk tingkat tiang adalah jenis S. parvifolia, tingkat pancang ialah jenis S. agami, dan tingkat semai yaitu jenis S. atrinervosa. Permudaan alam kelompok jenis non dipterokarpa yang paling dominan untuk tingkat tiang adalah M. malaccensis, tingkat pancang dan semai yang paling dominan ialah Koilodepas sp. Indeks keanekaragaman jenis vegetasi pada hutan sekunder bekas tebangan potensi rendah (tidak produktif) masih tergolong tinggi sampai sedang. Kondisi hutan sekunder KHDTK Labanan tidak memerlukan pengayaan karena telah memenuhi kriteria kecukupan jumlah vegetasi di tingkat pohon dan tiang.

\section{B. Saran}

Hutan sekunder tua dengan potensi masih rendah di KHDTK Labanan perlu segera dilakukan pemetaan dan pemeliharaan agar suksesi vegetasi alaminya tetap bertahan terutama untuk jenis-jenis komersial, sehingga potensi jenis komersial dipterokarpa dan nondipterokarpa dapat meningkat tanpa pengayaan.

\section{UCAPAN TERIMA KASIH}

Ucapan terima kasih disampaikan kepada: (1) Balai Besar Penelitian dan Pengembangan Ekosistem Hutan Dipterokarpa (BP2EHD) sebagai institusi yang telah membiayai kegiatan penelitian; (2) Dr. Darwo sebagai koordinator kegiatan penelitian yang telah membimbing dan mengarahkan dalam analisis data dan penyusunan artikel ini; (3) Dr. Farida Herry Susanty sebagai ketua kelompok peneliti manajemen hutan yang telah memberikan masukan dan saran pada artikel ini; (4) Para teknisi B2P2EHD yang telah membantu kegiatan penelitian di lapangan; dan (5) Kepala KPH Berau Barat, Kabupaten Berau, atas kerjasama dan bantuannya di lapangan.

\section{DAFTAR PUSTAKA}

Adman, B. (2012). Pemulihan, potensi jenis pohon lokal cepat tumbuh untuk batubara, lingkungan lahan pascatambang (Boedi Hendrarto (ed.); 1st ed.). Universitas Diponegoro.

Amirta, R., Angi, E.M., Ramadhan, R., Kusuma, I.W., Wiati, C.B., \& Haqiqi, M.T. (2017). Potensi Pemanfaatan Macaranga. Mulawarman University 
Press. Samarinda. Mulawarman University PRESS.

Arbainsyah, de Iongh, H.H., Kustiawan, W., \& de Snoo, G.R. (2014). Structure, composition and diversity of plant communities in FSC-certified, selectively logged forests of different ages compared to primary rain forest. Biodiversity and Conservation, 23(10), 2445-2472.

https://doi.org/10.1007/s10531-0140732-4

Asmayannur, I., \& Syam, Z. (2012). Analisis vegetasi dasar di bawah tegakan jati emas (Tectona grandis L.) dan jati putih (Gmelina arborea Roxb.) di Kampus Universitas Andalas. Jurnal Biologi, 1(2), 172177.

Denny, \& Kalima, T. (2016). Keanekaragaman tumbuhan obat pada hutan rawa-gambut Punggualas, Taman Nasional Sebangau, Kalimantan Tengah. Buletin Plasma Nutfah, 22(2), 137-148.

Fajri, M., \& Saridan, A. (2012). Kajian ekologi Parashorea malaanonan Merr di Hutan Penelitian Labanan Kabupaten Berau, Kalimantan Timur. Jurnal Penelitian Dipterokarpa, 6 (2), 141-154.

Fajri, M., \& Garsetiasih, R. (2019). Komposisi jenis vegetasi lahan pasca tambang galian $\mathrm{C}$ di KHDTK Labanan, Kabupaten Berau. Jurnal Penelitian Hutan Dan Konservasi Alam, $16 \quad$ (2), 101-118. https://doi.org/10.20886/jphka.2019.1 6.2.101-118

Hadiah, J.T, Yuzammi., \& Purnomo, D.W. (2019). Kajian habitat dan populasi pasak bumi (Eurycoma longifolia Jack) di blok barat kawasan hutan konservasi PT Sabhantara Rawi Sentosa, Kutai Timur, Kalimantan Timur. Buletin Kebun Raya, 22 (1), 3146.

Herianto, H. (2017). Keanekaragaman jenis dan struktur tegakan di areal tegakan tinggal. Jurnal Daun: Jurnal Ilmiah
Pertanian dan Kehutanan, 4 (1), 3846.

https://doi.org/10.33084/daun.v4i1.10 4

Narahari I.F., Ostertag, R., Asner, G.P., Cordell, S., Hubbell, S.P., \& Sack, L. (2014). Trade offs in seedling growth and survival within and across tropical forest microhabitats. Ecology and Evolution, 4(19), 3755-3767.

Ismaini, L., Lailati, M., Rustandi, \& Sunandar, D. (2015). Analisis komposisi dan keanekaragaman tumbuhan di Gunung Dempo, Sumatera Selatan. 1(6), 1397-1402. https://doi.org/10.13057/psnmbi/m010 623

Istomo, \& Dwisutono, A.N. (2016). Struktur dan komposisi tegakan serta sistem perakaran tumbuhan pada kawasan Karst di Taman Nasional Bantimurung-Bulusaraung, Resort Pattunuang-Karaenta. Jurnal Silvikuktur Tropika, 7(1), 58-67.

Istomo, \& Hartarto, W. (2019). Komposisi jenis dan struktur tegakan berbagai formasi hutan di Resort Bama Taman Nasional Baluran, Jawa Timur. Jurnal Silvikultur Tropika, 10(02), 75-82.

Hilwan, I. (2012). Komposisi jenis dan struktur tegakan pada areal bekas tebangan di PT Salaki Summa Sejahtera, Provinsi Sumatera Barat. Jurnal Silvikultur Tropika, 3(3), 155160.

Iwanaga, H., Teshima, K.M., Khatab, I.A., Inomata, N., Finkeldey, R., Siregar, I.Z., Siregar, U.J., \& Szmidt, A.E. (2012). Population structure and demographic history of a tropical lowland rainforest tree species Shorea parvifolia (Dipterocarpaceae) from Southeastern Asia. Ecology and Evolution, 2(7), 1663-1675. https://doi.org/10.1002/ece3.284

Karmilasanti, \& Abdurachman. (2017). Teknik Silvikultur untuk Rehabilitasi Hutan Sekunder. (Laporan Hasil Penelitian). B2P2EHD.

Keputusan Menteri Kehutanan Republik 
Indonesia Nomor: SK.64/MenhutII/2012 tentang Penetapan Kawasan Hutan Dengan Tujuan Khusus untuk Hutan Penelitian Lebanan yang Terletak di Kabupaten Berau, Provinsi Kalimantan Timur Seluas 7.959,10 Hektar.

Kenfack, D., Chuyong, G.B., Condit, R., Russo, S.E., dan Thomas, D. (2014). Demographic variation and habitat specialization of tree species in a diverse tropical forest of Cameroon. Forest Ecosystems Journal, 1(1), 1-13.

[KLHK] Kementerian Lingkungan Hidup dan Kehutanan. (2018). Statistik Lingkungan Hidup dan Kehutanan. Jakarta: Pusat Data dan Informasi KLHK.

https://doi.org/10.1017/CBO9781107 415324.004.

Kuswanda, W., \& Barus, S. (2017). Keanekaragaman dan penetapan 'umbrella species' satwaliar di taman nasional Gunung Leuser. Jurnal Penelitian Kehutanan Wallacea, 6(2), 113-123.

Kuswandi, R., Sadono, R., Supriyatno, N., \& Marsono, D. (2015). Keanekaragaman struktur tegakan hutan alam bekas tebangan berdasarkan biogeografi di Papua. Jurnal Manusia dan Lingkungan, 22(2), 151-159.

Margono, B.A., Potapov, P.V., Turubanova, S., Stolle, F., \& Hansen, M.C. (2014). Primary forest cover loss in indonesia over 2000-2012. Nature Climate Change, 4(8), 730-735. https://doi.org/10.1038/nclimate2277.

Mukrimin. (2011). Analisis potensi tegakan hutan produksi di Kecamatan Parangloe, Kabupaten Gowa. Jurnal Hutan dan Masyarakat, 6, 67-73.

Peraturan Direktur Jenderal Planologi Kehutanan Nomor. P/I/VIIIPSDH/2015 tentang Pedoman Pemantauan Penutupan Lahan.

Peraturan Direktur Jenderal Konservasi Sumber Daya Alam dan Ekosistem. Nomor. P.12/KSDAE-Set/2015 tentang Pedoman Tata Cara Penanaman dan Pengkayaan Jenis dalam Rangka Pemulihan Ekosistem Daratan pada Kawasan Suaka Alam dan Kawasan Pelestarian Alam.

Peraturan Menteri Kehutanan Republik Indonesia Nomor. P.64/MenhutII/2014tentang Penerapan Silvikultur dalam Areal Izin Usaha Pemanfaatan Hasil Hutan Bukan Kayu Restorasi Ekosistem pada Hutan Produksi.

Pryde, E.C., Holland, G.J., Watson, S.J., Turton, S.M., \& Nimmo, D.G. (2015). Conservation of tropical forest tree species in a native timber plantation landscape. Forest Ecology and Management, 339, 96-104. https://doi.org/10.1016/j.foreco.2014. 11.028

Samsoedin \& Heriyanto. (2010). Komposisi jenis dan struktur hutan terganggu dataran rendah di kompleks hutan Sungai Lepan, Sei Serdang, Taman Nasional Gunung Leuser, Sumatera Utara Jurnal Penelitian Hutan dan Konservasi Alam, 7(3), 299-314.

Sari, N., \& Karmilasanti. (2015). Kajian tempat tumbuh jenis Shorea smithiana, S. johorensis dan S. leprosula di PT ITCI Hutani Manunggal, Kalimantan Timur. Jurnal Penelitian Ekosistem Dipterokarpa, 1(1), 15-28. https://doi.org/10.20886/jped.2015.1.1 $.15-28$

Saridan, A. (2012). Keragaman jenis dipterokarpa dan potensi pohon penghasil minyak keruing di hutan dataran rendah Kabupaten Berau, Kalimantan Timur. Jurnal Penelitian Dipterokarpa, 6(2), 75-83. https://doi.org/10.20886/jped.2012.6.2 $.75-84$

Saridan, A., \& Soegiharto, S. (2012). Struktur tegakan tinggal pada uji coba pemanenan di hutan penelitian Labanan, Kalimantan Timur. Jurnal Penelitian Hutan dan Konservasi Alam, 9(3), 239-249. https://doi.org/10.20886/jphka.2012.9. 


\subsection{9-249}

Saridan, A., \& M.Fajri. (2014). Potensi jenis dipterokarpa di hutan penelitian Labanan, Kabupaten Berau, Kalimantan Timur. Jurnal Penelitian Dipterokarpa, 8(1), 7-14.

Saridan, A. \& Wahyudi, A. (2017). Eksplorasi jenis-jenis dipterokarpa potensial di Kalimantan Tengah. Jurnal Penelitian Ekosistem Dipterokarpa, 3(1), 23-32. http://dx.doi.org/10.20886/jped.2017. 3.1.23-32.

Seng, H.W., Ling, P.S., Lau, P., \& Jusoh, I. (2011). Sequence variation in the cellulose synthase (spcesal) gene from Shorea parvifolia mother trees. Pertanika Journal of Tropical Agricultural Science, 34(2), 317-323.

Soerianegara, I., \& Indrawan, A. (n.d.). (2014). Ekologi Hutan Indonesia. Laboratorium Ekologi Hutan Fakultas Kehutanan IPB. Bogor.

Susanty, F.H. (2015). Status Riset 25 Tahun Plot STREK. Balai Besar Penelitian dan Pengembangan Ekosistem Hutan Dipterokarpa. Samarinda

Utama, A.P., Syamsuardi, \& Arbain, A. (2012). Studi marfometrik daun makaranga thou di hutan pendidikan dan penelitian biologi (HPPB). Jurnal
Biologi Universitas Andalas, 1(1), 5462.

Van Welzen, P. C. (2010). Revision of the asian genus Koilodepas (Euphorbiaceae). Annals of The Missouri Botanical Garden, 97(2), 218-234. https://doi.org/10.3417/2007149.

Widiyatno, Soekotjo, Naiem, M., Hardiwinoto, S., \& Purnomo, S. (2011). Pertumbuhan meranti (Shorea spp.) pada sistem tebang pilih tanam jalur dengan teknik silvikultur intensif (TPTJ-SILIN). Jurnal Penelitian Hutan dan Konservasi Alam, 8(4), 373-383.

https://doi.org/10.20886/jphka.2011.8. 4.373-383

Widiyatno, Budiadi, Suryanto, P., Rinarno, Y., Prianto, S., Hendro, Y., Hosaka, T., \& Numata, S. (2017). Recovery of vegetation structure, soil nutrients and late-succesion species after shifting cultivation in Central Kalimantan, Indonesia. Journal Forest Rehabilitation, 29(2), 151-162. 
Lampiran (Appendix) 1. Jenis vegetasi kelompok komersial pada hutan sekunder di KHDTK Labanan (Commercial vegetation at secondary forest in KHDTK Labanan)

\begin{tabular}{|c|c|c|c|c|}
\hline No & $\begin{array}{l}\text { Nama lokal } \\
\text { (Local name) }\end{array}$ & $\begin{array}{c}\text { Nama } \\
\text { perdagangan } \\
\text { (Commercial } \\
\text { name) } \\
\end{array}$ & $\begin{array}{c}\text { Nama ilmiah } \\
\text { (Scientific name) }\end{array}$ & Famili (Family) \\
\hline \multicolumn{5}{|c|}{ rpa (Commercial diptero } \\
\hline 1 & Keruing & Keruing & Dipterocarpus eurynchus & Dipterocarpaceae \\
\hline 2 & Merawan & Merawan & Hореа сеrnua & Dipterocarpaceae \\
\hline 3 & Merawan & Merawan & Hopea pachycarpa & Dipterocarpaceae \\
\hline 4 & Meranti sarang punai & Meranti & Shorea parvifolia & Dipterocarpaceae \\
\hline 5 & Meranti putih & Meranti & Shorea agami & Dipterocarpaceae \\
\hline 6 & Meranti kuning bukit & Meranti & Shorea angustifolia & Dipterocarpaceae \\
\hline 7 & Selangan batu & Meranti & Shorea atrinervosa & Dipterocarpaceae \\
\hline 8 & Meranti kuning & Meranti & Shorea collaris & Dipterocarpaceae \\
\hline 9 & Selangan batu & Meranti & Shorea excelliptica & Dipterocarpaceae \\
\hline 10 & Damar asam & Meranti & Shorea hopeifolia & Dipterocarpaceae \\
\hline 11 & Meranti merah & Meranti & Shorea macroptera & Dipterocarpaceae \\
\hline 12 & Meranti sarang punai & Meranti & Shorea parvifolia & Dipterocarpaceae \\
\hline 13 & Tengerawan kuning & Meranti & Shorea parvistipulata & Dipterocarpaceae \\
\hline 14 & Awang lanying & Meranti & Shorea smithiana & Dipterocarpaceae \\
\hline 15 & Meranti & Meranti & Shorea sp. & Dipterocarpaceae \\
\hline 16 & Resak & Resak & Vatica oblongifolia & Dipterocarpaceae \\
\hline \multicolumn{5}{|c|}{ B. Komersial non dipterokarpa (Commercial non dipterocarp) } \\
\hline 1 & Eboni & Eboni & Diospyros sp. & Ebenaceae \\
\hline 2 & Rengas & Rengas & Gluta renghas & Anacardiaceae \\
\hline 3 & Asem busur & Asem busur & Mangifera macrocarpa & Anacardiaceae \\
\hline 4 & Durian & Durian & Durio graveolens & Bombaceae \\
\hline 5 & Kenari & Kenari & Canarium denticulatum & Burseraceae \\
\hline 6 & Paruh enggang & Paruh enggang & Dacryodes rostrata & Burseraceae \\
\hline 7 & Simpur & Simpur & Dillenia excelsa & Dilleniaceae \\
\hline 8 & Terap & Terap & Arthocarpus sp. & Moraceae \\
\hline 9 & Pohon perah & pohon perah & Elateriospermum tapos & Euphorbiaceae \\
\hline 10 & Mahang & Mahang & Macaranga gigantae & Euphorbiaceae \\
\hline 11 & Mahang & Mahang & Macaranga hypoleuca & Euphorbiaceae \\
\hline 12 & Bayur & Bayur & Mallotus sp. & Euphorbiaceae \\
\hline 13 & Ketiau & Ketiau & Medhuca malaccensis & Euphorbiaceae \\
\hline 14 & Asam keranji & asam & Dialium sp. & Fabaceae \\
\hline 15 & Kempas & kempas & Kompassia malaccensis & Fabaceae \\
\hline 16 & Malapari & Malapari & Pongamia sp. & Fabaceae \\
\hline 17 & Laban & Laban & Vitex vestita & Lamiaceae \\
\hline 18 & Medang & Medang & Litsea sp. & Lauraceae \\
\hline 19 & Putat & Putat & Barringtonia sp. & Lecythidaceae \\
\hline
\end{tabular}


Struktur Dan Komposisi Jenis Vegetasi di Hutan Sekunder:

Studi Kasus KHDTK Labanan Provinsi Kalimantan Timur

Karmilasanti, dan/and M. Fajri

Lampiran (Appendix) 1. Lanjutan (To be continue)

\begin{tabular}{|c|c|c|c|c|}
\hline No & $\begin{array}{l}\text { Nama lokal } \\
\text { (Local name) }\end{array}$ & $\begin{array}{c}\text { Nama } \\
\text { perdagangan } \\
(\text { Commercial } \\
\text { name })\end{array}$ & $\begin{array}{c}\text { Nama ilmiah } \\
\text { (Scientific name) }\end{array}$ & Famili (Family) \\
\hline 20 & Durian hutan & Durian & Durio gravculen & Malvaceae \\
\hline 21 & Terap & Terap & Artocarpus anisophyllus & Moraceae \\
\hline 22 & Terap & Terap & Artocarpus elasticus & Moraceae \\
\hline 23 & Kayu ara & Kayu ara & Ficus sp. & Moraceae \\
\hline 24 & Keurea & Keurea & Knema elmeri & Myristicaceae \\
\hline 25 & Pala & Pala & Myristica villosa & Myristicaceae \\
\hline 26 & Jambu-jambu & Jambu-jambu & Syzygium sp. & Myrtaceae \\
\hline 27 & Pampaning bitik & Pampaning bitik & Lithocarpus sp. & Pagaceae \\
\hline 28 & Nyalin & Nyalin & Xanthophyllum sp. & Polygalaceae \\
\hline 29 & Rambutan hutan & Rambutan hutan & Nephelium sp. & Sapindaceae \\
\hline 30 & Katiau & Katiau & Medhuca malaccensis & Sapotaceae \\
\hline
\end{tabular}

Malvaceae 